\title{
Investigation on Plasma Cutting of Two Separate Thin Steel Sheets Simultaneously Using Taguchi Experimental Design Approach
}

\author{
Adel Gani \\ Engineering Doctorate Researcher, Advanced Manufacturing, University of Strathclyde, Department of Design \\ Manufacturing and Engineering Management, 75 Montrose Street, Glasgow, G1 1XJ, Scotland, UK. \\ Tel: +447581147753 \\ adel.gani@strath.ac.uk \\ Prof. William Ion \\ Professor, Advanced Manufacturing, University of Strathclyde, Department of Design Manufacturing and \\ Engineering Management, 75 Montrose Street, Glasgow, G1 1XJ, Scotland, UK. \\ Tel: +441415482323 \\ w.j.ion@strath.ac.uk \\ Dr. Erfu Yang \\ Chancellor Fellow, Advanced Manufacturing, University of Strathclyde, Department of Design Manufacturing \\ and Engineering Management, 75 Montrose Street, Glasgow, G1 1XJ, Scotland, UK. \\ Tel: +441415745279 \\ erfu.yang@strath.ac.uk
}

\begin{abstract}
This article investigates the ability of using plasma machining for cutting simultaneously two parallel thin layers at different gap distances. The main aim of this work is to identify whether this technology if mechanised can be more appropriate than using a circular saw to process a three-dimensional structure material such as double layers, box sections or rails. This research is aimed at those working in the automotive industry and converting vehicles. Test models were built for the experiments using $0.7 \mathrm{~mm}$ thick steel sheets DCO1 grade, similar material used for some underbody vehicle chassis parts. Serie of cuts were carried out first to analyse the ability of the plasma to perform a simultaneous cutting in two separate sheets with an air gap, followed by tests to minimise the deformation and heat affected zones on the top sheets adopting Taguchi methodology. Parameters analysed included cutting speed, intensity, pressure, and gap distance between the two sheets. The specimens collected were assessed for quality including Kerf, dross, hardness, offset distance between the top and bottom cut edge, sheet deformation and heat affected zones. The experiments showed the possibility to use plasma to cut in more than one sheet with one pass even if layers are separated with air distance. Analysis of variance showed that the input-controlled parameters which had the most influence on the top sheet deformation and HAZ were respectively intensity and gap. Regression equations showed a good model fit and the relationship between the input and output variables were strong. Results revealed that plasma could be an alternative tool if optimised to process three-dimensional structure parts, but it is dependent on the tolerances and the quality required.
\end{abstract}

KEYWORDS: Plasma cutting; Double Sheet; Deformation; Affected Zone; Taguchi method; regression model.

\section{Introduction}

Plasma arc cutting is a thermal process that uses an ionised gas which can reach temperature of $30000^{\circ} \mathrm{C}[1]$ ejected at approximatively the velocity of the sound or even higher, this is known as the fourth state of the matter[2]. The recommended steel material thickness of cut range for plasma is usually between 5 to $40 \mathrm{~mm}$ for standard machines[3] the range can vary depending on the plasma model[4]. The more advanced industrial plasma models can cut up to 150 $\mathrm{mm}$ thick$[5][6]$. The technique can usually process any electric conductive material. Plasma is widely used in the industry 
for cutting and profiling, it provides a good cutting speed, low investment and operation cost compared to abrasive water jet or laser[7][8].

Cutting simultaneously a double layered structure with one pass (Figure 1) using plasma technology has never been explored in the past and was assumed to be impossible according to a research paper published previously by D. Krajcarzin where he conducted a comparative study of cutting materials using abrasive waterjet, laser and plasma[9]. The tools used primarily to process a three-dimensional structure are mechanical shears primarily circular or reciprocating saws known as traditional cutting. However, this turned out to have some limitations, for instance, profiling issues and time consuming[10]. Plasma was found to be productive when a linear cutting or a 2D profiles are involved but if a second plan of cut is required then the cutting process become unknown, engineers usually use traditional tools[11]. Therefore, investigating on plasma cutting a 3D structures was necessary to expand the boundaries of their application and field of use.

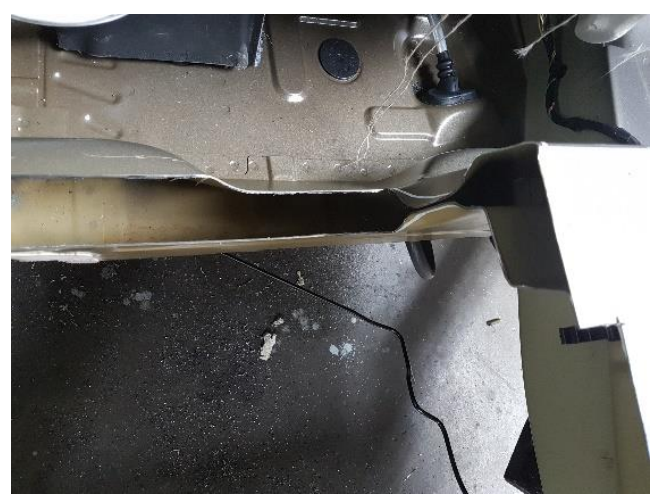

Figure 1 Underbody Chassis Rear Floor Cut Out (Double-Layered Zone) Peugeot Partner

Experimental method is a valid way widely used by researchers to problem solve, gain new knowledge about an unknown process and factors[12]. To identify the suitable cutting parameters for a new component Trial-and-Error approach can be used, this involves repeating tests and changing combination until results are obtained[13][14]. Taguchi is an effective way known as a robust design used for data collection and analysis. The technique is used for experimental research to optimise variables, reduce time, energy consumption, cut the cost and the number of tests required from full factorial to a minimum number of trial needed but remain accurate[15].

There are many researchers used Taguchi based Experiment design to optimise plasma cutting process, for instance, $\mathrm{H}$. Ramakrishnan et al[8] investigated on the quality cut including surface roughness, HAZ and kerf of SS321 steel grade, plasma parameters was optimised using Taguchi method using L9 orthogonal array, the variables assessed were gas pressure, torch stand-off, current and cutting speed at three levels, Taguchi allowed to reduce trial from $3^{4}=81$ to only 9 trials. K. Rana et al[16] investigated on air plasma cutting quality cut of mild steel mainly to reduce the HAZ, Taguchi method was used to optimise the parameters, cutting speed, torch stand-off, air pressure and current at three levels. J. O. Abe et al[17] used Taguchi to optimise plasma parameters to cut a Titanium material using 4 variables at three levels.

The aim of this research was to fill the knowledge gap of whether the plasma technology was able to effectively cut simultaneously a three-dimensional structure such as double-layered parts. The work sought to solve an industry problem and cut the processing time down by avoiding cutting one sheet at time. This would be beneficial for the automotive industry involved primarily in converting vehicles and sectioning the underbody chassis floor. The concept was to come up with a suitable automated plasma cutting tool and control their parameters to perform the task adequately and tackle the problems addressed before.

The objectives of the study were to figure out using a trial-and-error methodology in three different experimental phases the effective parameters that can perform a cut in two layers simultaneously. Therefore, jig models were assembled for the tests using similar sheets $0.7 \mathrm{~mm}$ thick at different gaps distance to create a three-dimensional structure. Then assess and optimise the process using Taguchi method to reduce the effect of the heat generated by plasma on the top sheet material. Identify the most influential parameters for the process. Assess the strength of the variable's relationship for the top sheet. Lastly, validate.

Plasma arc cutting acquired a massive ground in the industry these last year's[18]. Tremendous amount of research was carried out on plasma machining. However, scientific publications on plasma cutting process remain limited and can be classified only in two categories either in metal plate analysis or plasma study[19]. Dattu B. Ghane assessed the effect 
of plasma parameters and the nozzle type on mild steel cutting quality[20]. Yahya H. Celik looked at ways to optimize the plasma settings to reduce heat affected zones and roughness for a different mild steel material thicknesses[21]. Another experimental research made by Dr. Andjela Lazarevic[22] on stainless steel material to assess the influence of the input parameters on the output, also to process materials such as Hardox 400 and assess the quality[7] or titanium[23]. S.M.Illi carried out a research on what drives the cost in plasma[24]. Evan Floyd looked at the characteristic of the fume generated during the plasma cutting[25]. T. Kavka assessed experimentally the effect of different gases on the performance of plasma cutting[26]. A research was performed on dual material aluminum and steel processed using latest plasma technology known as high density model[27], other research on sandwich or structured thin materials also was carried out previously[10,28].

These articles were primarily assessing plasma cutting quality in two-dimensional plan linear cut. However, there was no documentation available which assessed plasma if a second plan of cut is required for instance how plasma would perform on three-dimensional parts such as double-layered or box section. D. Krajcarz[5] reviewed the three main best cutting methods used to cut metals including abrasive waterjet, laser and plasma, their conclusion suggested only waterjet can perform a cut in multi-layered sheets. L. Schleuss et al[28] stressed that cutting a three-dimensional structures was not a well-known field. S. Tossen et al[29] highlighted in their experimental research article that only $20 \%$ of the plasma energy was used to cut the material and the remaining energy was whether dissipated in the plate or exit the kerf. The energy exiting the kerf could be re-used to process additional layer, this could be beneficial for businesses where vehicles are converted in the cut-out floor stage, as some parts in the underbody chassis are made of two layers separated with an air gap, this would cut the processing time down by avoiding cutting some zones of the chassis in two sides (cutting from top side of chassis floor and from the underneath side the car).

\section{Materials and experimental set up}

Material used for the experiments was two identical $0.7 \mathrm{~mm}$ thick sheets cold rolled drawing steel DC01 grade, similar steel used for some underbody vehicle chassis floor parts[30]. The chemical composition of the low carbon steel material is $0.12 \%$ Carbon, $0.6 \%$ Manganese, $0.045 \%$ phosphorus and $0.45 \%$ Sulfur[31]. The mechanical properties of the metal are given in the table 1 below:

Table 1 Mechanical Properties[31]

\begin{tabular}{ccccccccc}
\hline $\begin{array}{l}\text { Density } \\
(\mathbf{p}) \mathbf{k g} / \mathbf{d m}^{\mathbf{3}}\end{array}$ & $\begin{array}{l}\text { Young's } \\
\text { Modulus } \\
\text { E(Gpa) }\end{array}$ & $\begin{array}{l}\text { Yield } \\
\text { Stress } \\
\text { Y(Mpa) }\end{array}$ & $\begin{array}{l}\text { Tensile } \\
\text { Stress } \\
\text { R(Mpa) }\end{array}$ & $\begin{array}{l}\text { \% } \\
\text { Elongation } \\
\text { A/80mm } \\
\text { gauge }\end{array}$ & $\begin{array}{l}\text { Anisotropy } \\
\text { (r) }\end{array}$ & $\begin{array}{l}\text { Poisson's } \\
\text { ratio (v) }\end{array}$ & $\begin{array}{l}\text { Strain } \\
\text { hardening } \\
\text { exponent } \\
\text { (n) }\end{array}$ & $\begin{array}{l}\text { Strength } \\
\text { Coefficient } \\
\mathbf{k}\end{array}$ \\
\hline 7.83 & 210 & $140-280$ & $270-710$ & Min 28 & 1.53 & 0.35 & 0.21 & 619 \\
\hline
\end{tabular}

The experiment was divided into three phases, the first tests were primarily completed to find out the ability of the plasma to cut with one pass through two separate sheets using a trial-and-error methodology. Plasma parameters were varied each time to achieve a second cut simultaneously on the lower sheet. Gap distance between the top and bottom layers was incremented gradually to figure out the maximum gap which allows a cut in two sheets simultaneously e.g., $16 \mathrm{~mm}, 25 \mathrm{~mm}$, and $35 \mathrm{~mm}$. The second tests were carried out to identify the effective parameters that can be used as a reference for a fixed gap distance $20 \mathrm{~mm}$ (approximatively the average distance between 16mm and $25 \mathrm{~mm}$ gap), these parameters would be used as a starting point in the following experiment. The third tests were carried out to optimise the parameters and reduce material deformation and heat affected zones on the top sheet using Taguchi approach.

\subsection{Plasma Capability Analysis}

Two identical sheets were assembled to create a three-dimensional structure part using bolts, nuts, washers, and spacers to keep the two sheets separated at a desired gap distance. The number of trials performed in this stage were 11 cuts of $150 \mathrm{~mm}$ straight lines starting from the edge as seen in the picture 2 below. The input parameters were changed after each trial. Gap distance between the two sheets was varied starting from $16 \mathrm{~mm}, 25 \mathrm{~mm}$ then $35 \mathrm{~mm}$. CNC plasma was used for this experiments Hypertherm Powermax 1250 G3 Series Torchmate T80M automatic distance adjustment torchworkpiece[32]. The parameters that resulted to a simultaneous cut in both layers are given in the table 2 below. 


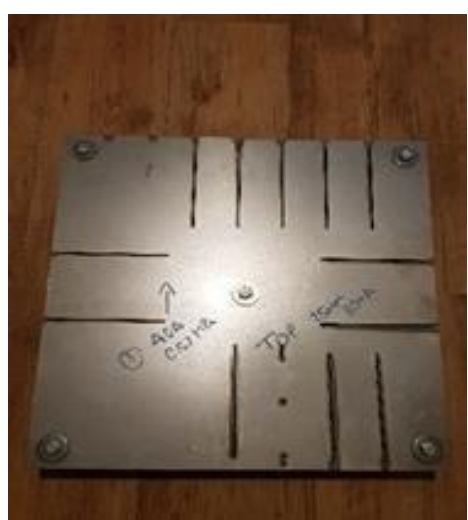

(a)

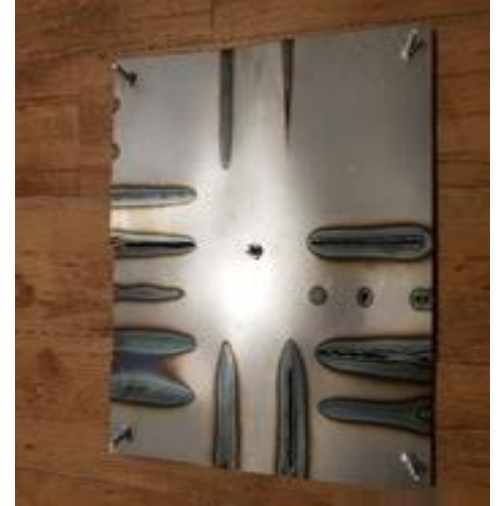

(b)

Figure 2 Experiment Models for the first test, (a) Top sheet of the model, (b) Bottom sheet of the test model

Table 2 Parameters resulted to a cut in both layers

\begin{tabular}{|c|c|c|c|}
\hline $\begin{array}{l}\text { Gap Distance } \\
\text { between the two } \\
\text { layers }\end{array}$ & $\begin{array}{l}\text { Pressure } \\
\text { (Psi) }\end{array}$ & $\begin{array}{l}\text { Intensity } \\
\text { (A) }\end{array}$ & $\begin{array}{l}\text { Cutting } \\
\text { Speed } \\
(\mathrm{mm} / \mathrm{min})\end{array}$ \\
\hline \multirow[t]{2}{*}{16 mm Gap } & 90 & 70 & 2000 \\
\hline & 80 & 90 & 2000 \\
\hline 25 mm Gap & 75 & 90 & 2000 \\
\hline
\end{tabular}

The first tests results confirmed the assumption made and demonstrated that the energy exiting the first sheet can be reused to make an additional cut on neighbouring layer. Hence, cutting two distant layers simultaneously with plasma was possible but restricted by the gap. The $35 \mathrm{~mm}$ gap trials did not achieve a full cut on the lower layer.

\subsection{Parameters Identification}

Second tests were necessary to figure out what would be the adequate parameters required to make an effective cut for a fixed gap. New three-dimensional structure part was assembled for this experiment, identical to the first model but the gap was fixed to $20 \mathrm{~mm}$ as explained before. The settings were chosen randomly using trial and error method. Among 16 trials performed the ones that resulted to a cut in both layers were recorded in the table 3 below. The quality of the cut was assessed visually and the parameters that achieved the best result was chosen as a reference for the next experiment to optimise the process.

Table 3 Test 2 cutting results

\begin{tabular}{cccc}
\hline Tests & $\begin{array}{c}\text { Pressure } \\
\text { (Psi) }\end{array}$ & $\begin{array}{c}\text { Intensity } \\
\text { (A) }\end{array}$ & $\begin{array}{c}\text { Cutting Speed } \\
(\mathbf{m m} / \mathbf{m i n})\end{array}$ \\
\hline Trial Number 7 & 80 & 45 & 500 \\
\hline Trial Number 8 & 80 & 45 & 750 \\
\hline Trial Number 9 & 80 & 45 & 700 \\
\hline Trial Number 12 & 80 & 35 & 500 \\
\hline Trial Number 13 & 80 & 33 & 500 \\
\hline
\end{tabular}




\begin{tabular}{llll}
\hline Trial Number 14 & 80 & 30 & 400 \\
\hline Trial Number 16 & 80 & 25 & 300
\end{tabular}

Trials that showed a cut on both sides of the test model were successively number 7, 8, 9, 12, 13, 14 and 16 . The best quality cut was obtained using parameters of the trial number 12 using pressure 80 psi, Intensity $35 \mathrm{~A}$ and cutting speed $500 \mathrm{~mm} / \mathrm{min}$.

\subsection{Taguchi Design}

To find out if the effect of the plasma cutting heat on the top sheet can be reduced, three models were assembled for the third experiment at different gaps $10 \mathrm{~mm}, 15 \mathrm{~mm}$ and $20 \mathrm{~mm}$ as seen in the picture 3 . Taguchi was chosen as the approach for the experiment as this method can reduce the number of trials in this case from $3^{\wedge} 4=81$ to only 9 trials while at the mean time the accuracy is preserved. Parameters were optimised to reduce material deformation and heat affected zones of the top sheet of the models. Four input variables were selected including cutting speed, current, gas pressure and gap distance at three levels. Orthogonal array was defined and assigned nine trials L9 $\left(3^{\wedge} 4\right)$ as shown on the tables 4 and 5 below. Three trials for each model were performed, rectangles of $40 \times 150 \mathrm{~mm}$ were cut as shown in the pictures 4 below .

Table 4 Parameters and levels

\begin{tabular}{cccc}
\hline Parameters / Levels & L1 & L2 & L3 \\
\hline Gap between the two sheets(mm) & 10 & 15 & 20 \\
\hline Cutting Speed (mm/min) & 300 & 400 & 500 \\
\hline Intensity (A) & 25 & 30 & 35 \\
\hline Air Pressure (Psi) & 70 & 75 & 80 \\
\hline
\end{tabular}

Table 5 Orthogonal Array

\begin{tabular}{ccccc}
\hline Trials & $\begin{array}{c}\text { Gap } \\
(\mathbf{m m})\end{array}$ & $\begin{array}{c}\text { Cutting Speed } \\
(\mathbf{m m} / \mathbf{m i n})\end{array}$ & Intensity (A) & Pressure (Psi) \\
\hline Trial 1 & 20 & 500 & 35 & 80 \\
\hline Trial 2 & 20 & 400 & 30 & 75 \\
\hline Trial 3 & 20 & 300 & 25 & 70 \\
\hline Trial 4 & 15 & 500 & 30 & 70 \\
\hline Trial 5 & 15 & 400 & 25 & 80 \\
\hline Trial 6 & 15 & 300 & 35 & 75 \\
\hline Trial 7 & 10 & 500 & 25 & 70 \\
\hline Trial 8 & 10 & 400 & 35 & 80 \\
\hline Trial 9 & 10 & 300 & 30 & \\
\hline
\end{tabular}




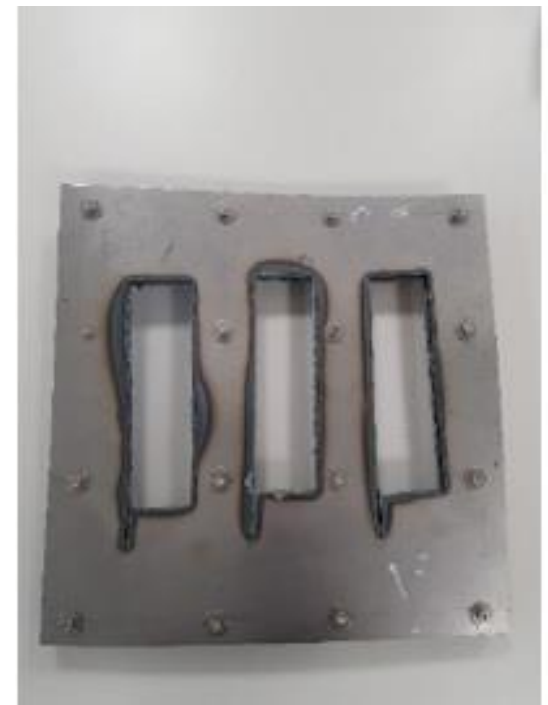

(a) Trial 7,8 and 9

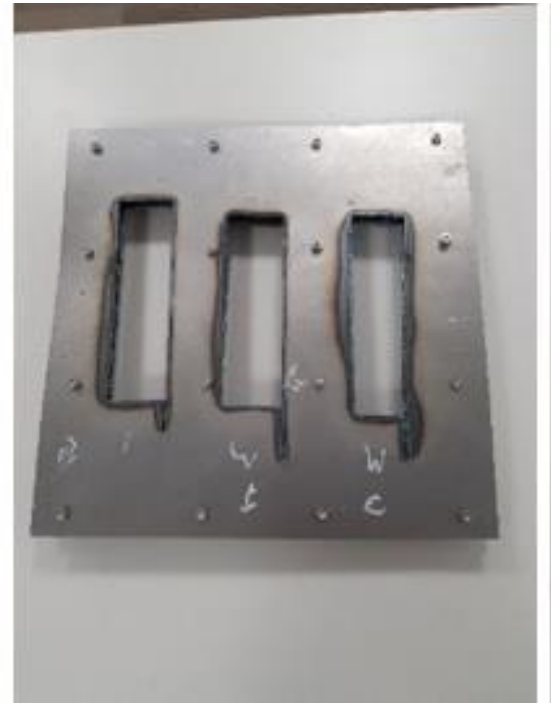

(b)Trial 4, 5 and 6

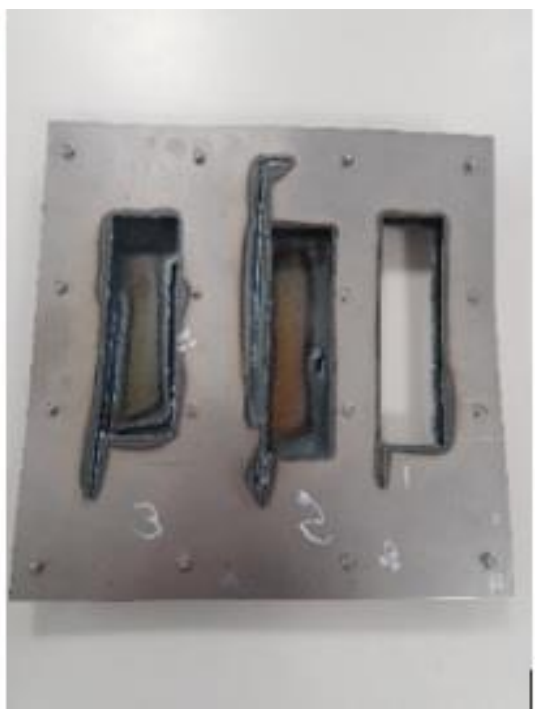

(c) Trial 1,2 and 3

Figure 3 Experimental models, (a) $10 \mathrm{~mm}$ model, (b) $15 \mathrm{~mm}$ model, (c) $20 \mathrm{~mm}$ model

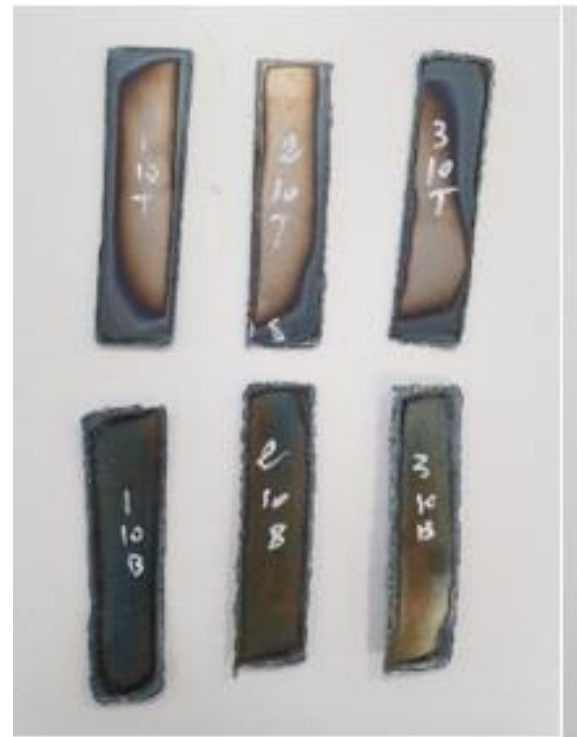

(a) Trial 7, 8 and 9
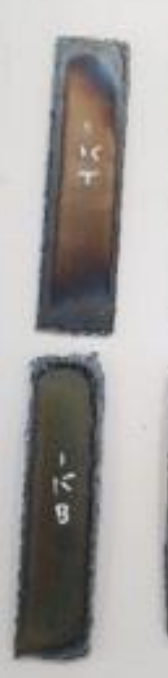

(b) Trial 4, 5 and 6

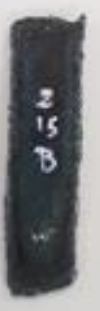

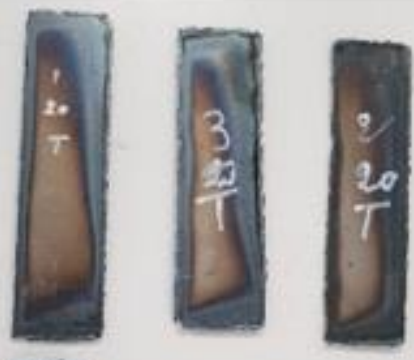

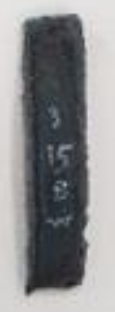

(c) Trial 1,2 and 3

Figure 4 Specimens Collected from the Models, Top and Bottom Side, (a) $10 \mathrm{~mm}$ Gap Model Samples, (b) $15 \mathrm{~mm}$ gap Model Samples, (c) $20 \mathrm{~mm}$ gap Model Samples.

16 specimens collected from this experiment, Six from each model and three from each side. Samples were analysed to figure out if a second processing was necessary to remove the undesirable edge. Quality assessment included Kerf analysis, Dross, cut edge offset between the top and bottom sheet, Heat Affected Zones size and Sheet Deformation.

$20 \mathrm{~mm}$ gap model resulted to only four samples, three from the top and one from the bottom sheet, trial 3 resulted to an uncomplete half cut on the bottom sheet and the trial 2 performed only a very small length of cut. This might be the cause of the accumulation of the heat resulted to an increase in the gap between the two sheets. It was not possible to scan the two samples and assess the deformation. However, it was possible to assess the half sample obtained on the bottom sheet trial 3 for HAZ, hardness, kerf, dross, and the edge offset.

\section{Results}

\subsection{Surface Deformation}


Samples collected (16 rectangles $150 \times 40 \mathrm{~mm}, 0.7 \mathrm{~mm}$ thick) were scanned, the technique used to measure the deformation level was a 3D ATOS TripleScan state of the art technology surface analysis. The technology is widely used in metrology field within the automotive industry nowadays. The concept uses a non-contact blue light[33], for one single scan it can take up to 16 million points within the surface part assessed at high precision of 10 Microns[34]. The technique offers a better value compare to a conventional probe gauge where an accurate measurement is difficult to achieve in deformed or curved surfaces. Furthermore, this method was suggested by researchers as an efficient way to capture features detail in short time whether in small or large scale[35].

GOM inspect was used as a software to measure the maximum deformation of each specimen. Gaussian best fit virtual plan method was selected to construct the reference to measure the level. All values obtained were in millimetres, a deformation simulation was illustrated in the pictures below (see Fig 5 ) to show different level variations, zones with the red colour represents the areas with highest level of deformation compared to the plan constructed.

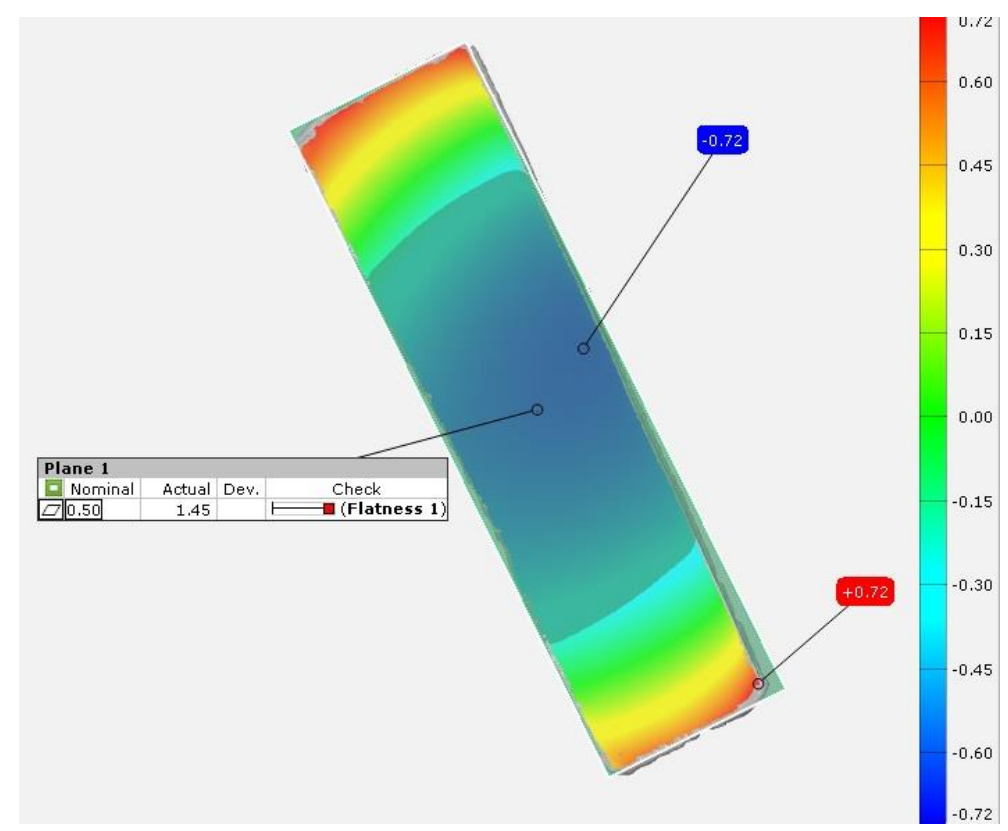

Fig 5 Scanned Specimen $10 \mathrm{~mm}$ gap model trail one top sheet

The sheets collected were assessed individually in the same process. The results showed different levels of deformation for all samples and the values obtained were displayed in the table 6 below.

Table 6 Surface Deformation and HAZ measured

\begin{tabular}{lccccc}
\hline Samples & \multicolumn{2}{c}{ Surface Deformation $(\mathbf{m m})$} & \multicolumn{2}{c}{ HAZ $(\mathbf{m m})$} \\
\cline { 2 - 6 } & & $\begin{array}{l}\text { Top } \\
\text { Sheets }\end{array}$ & $\begin{array}{l}\text { Bottom } \\
\text { Sheets }\end{array}$ & $\begin{array}{l}\text { Top } \\
\text { sheets }\end{array}$ & $\begin{array}{l}\text { Bottom } \\
\text { Sheets }\end{array}$ \\
\hline First Jig Model & Trial 1 & 0.55 & 3.50 & 0.844 & 2.36 \\
\cline { 2 - 6 } 20mm Air Gap & Trial 2 & 1.15 & $/$ & 1.126 & $/$ \\
\cline { 2 - 6 } & Trial 3 & 0.97 & $/$ & 1.222 & 3.089 \\
\hline Second Jig Model & Trial 4 & 1.03 & 3.67 & 0.947 & 2.191 \\
\cline { 2 - 7 } 15mm air Gap & Trial 5 & 0.91 & 3.33 & 0.714 & 3.446 \\
\cline { 2 - 6 } & Trial 6 & 0.85 & 3.90 & 1.441 & 3.230 \\
\hline Third Jig Model & Trial 7 & 1.45 & 3.72 & 0.632 & 1.924 \\
\cline { 2 - 6 } 10mm air Gap & Trial 8 & 0.42 & 2.03 & 0.834 & 1.781 \\
\cline { 2 - 6 } & Trial 9 & 1.12 & 2.82 & 0.682 & 1.245 \\
\hline
\end{tabular}

The results from the table showed that the deformation phenomenon on the bottom sheets was higher compared to the samples from the top sheets. Minimum value registered for the top sheet was $0.42 \mathrm{~mm}$ and a maximum deformation was $1.45 \mathrm{~mm}$ whereas the bottom samples exhibited a minimum deformation of $2.03 \mathrm{~mm}$ and a maximum of $3.9 \mathrm{~mm}$.

\subsection{Dross and Kerf}


Dross is the accumulation of unwanted material formed during the cutting process on the top or bottom cut edge[36]. The phenomenon can be caused by a number of factors such as high or low cutting speed, torch standoff, surface condition and worn consumable[37]. Gom Software was used to measure the Dross size, the highest value around the edges was registered, the measured values were verified also using a calliper. The analysis showed that the values on the top samples were varied from $1.3 \mathrm{~mm}$ trial 8 to $2.7 \mathrm{~mm}$ trial 2 . The bottom samples dross sizes were slightly higher $1.9 \mathrm{~mm}$ as a minimum value trial one and $3.3 \mathrm{~mm}$ as a maximum size obtained using trial 3 .

Kerf is the quantity of material removed from the material during the plasma cutting process, the width of the kerf is affected in general by the incorrect choice of the parameters such as slow cutting speed, high amperage or pressure and also by the orifice of the plasma nozzle. To achieve a correct parts size usually the CNC plasma needs to be adjusted from the software kerf compensation[38]. Gom analysis was used to measure the kerf, the values obtained were also checked and verified using a feeler tool. The top samples showed a smaller width sizes compared to the bottom ones with a minimum of $1.4 \mathrm{~mm}$ using parameters of the trial 5 and maximum of $1.9 \mathrm{~mm}$ obtained with trial 1 . The bottom samples exhibited a maximum width of $4.7 \mathrm{~mm}$ using trial number 9 and minimum size was $2.4 \mathrm{~mm}$ using trial 5 .

\subsection{Cut edge offset between the top and bottom sheet}

To measure the difference between the top and bottom samples, a calliper was used as a tool, this was also checked using for accuracy using the gom software. Trial 3 did not result to a full cut of the sample on the bottom sheet. However, the width and the length can still be measured using a calliper and obtain the approximative surface area. The offset between the two edges can also be calculated by measuring the deference between the top and bottom kerf. The results were recorded in the table 7 below. The analysis showed that samples obtained from the bottom of the model were slightly smaller than the ones collected from the top side and these were not identical. This meant that there was an offset between top sheets edge and bottom ones for the same trial.

Table 7 Cut Edge Offset Deviation

\begin{tabular}{|c|c|c|c|c|}
\hline Samples & & $\begin{array}{l}\text { Cut edge offset deviation }(\mathrm{mm}) \\
\text { Between top and bottom } \\
\text { specimens for each side }\end{array}$ & $\begin{array}{l}\text { Total Surface lost } \\
\text { of the bottom sample } \\
\left(\mathrm{mm}^{2}\right)\end{array}$ & $\begin{array}{l}\% \text { of the total } \\
\text { size lost }\end{array}$ \\
\hline \multirow{3}{*}{$\begin{array}{l}\text { First Jig Model } \\
\text { 20mm Air Gap }\end{array}$} & Trial 1 & 1.45 & 542.59 & $9 \%$ \\
\hline & Trial 2 & I & 1 & I \\
\hline & Trial 3 & 1.25 & 468.75 & $7.8 \%$ \\
\hline \multirow{3}{*}{$\begin{array}{l}\text { Second Jig Model } \\
\text { 15mm air Gap }\end{array}$} & Trial 4 & 1.15 & 431.71 & $7.2 \%$ \\
\hline & Trial 5 & 1.65 & 616.11 & $10.27 \%$ \\
\hline & Trial 6 & 1.35 & 505.71 & $8.43 \%$ \\
\hline \multirow{3}{*}{$\begin{array}{l}\text { Third Jig Model } \\
\text { 10mm air Gap }\end{array}$} & Trial 7 & 1.28 & 479.85 & $7.99 \%$ \\
\hline & Trial 8 & 1.1 & 413.16 & $6.89 \%$ \\
\hline & Trial 9 & 1.3 & 487.24 & $8.12 \%$ \\
\hline
\end{tabular}

Comparing the trials from the table above, the widest offset was obtained using parameters of the trial 5 with offset of $1.65 \mathrm{~mm}$ and surface loss of $616.11 \mathrm{~mm}^{2}$, the total reduction was $10.27 \%$, the lowest deviation was achieved using parameters of the trial number 8 for the smallest gap distance.

\subsection{Heat Affected Zones}

Heat Affected Zone (HAZ) is the volume material between the cut edge and the base material which the mechanical properties are altered due to high heat input and fast cooling. This area is weak compare to the unaffected base and can easily crack and cause problems, therefore it is undesirable for engineering applications. HAZ can be divided into four areas, the closest to the unaffected base material is called tempered zone, then partly changed area, recrystalised and grain growth area which are close to the cutting edge[39][40]. Different areas in the HAZ can be contrasted (heat tint) and visible due to high temperature distribution impact across the material and surface oxidation during a cut. HAZ size is usually depending on the material used, the quantity of heat applied and the length of exposure [40].

Samples collected from the experiments were prepared, sectioned, and mounted in a $40 \mathrm{~mm}$ diameter mould, the mounting press used was SimpliMet3000 Buehler automatic model and the Compound type was ProbeMet, pressed to 290bars at $150^{\circ} \mathrm{C}$. The specimens were polished with a rotating machine AutoMet300 Buehler model using successively sandpapers, P120, P240, P400, P800, P1200 Grit Sic, followed by a mirroring stage using $9 \mu \mathrm{m}$ and $3 \mu \mathrm{m}$ Metadi Supreme Diamond then $0.05 \mu \mathrm{m}$ MasterPrep Alumina solution. Lastly, samples were etched with $5 \%$ Nital acid[41] to expose the gains as 
seen in the picture 6 below. The specimens were analysed under the microscope Model LEICA DM12000M and measured the Heat affected zones size, results were summarised in the table 6 .

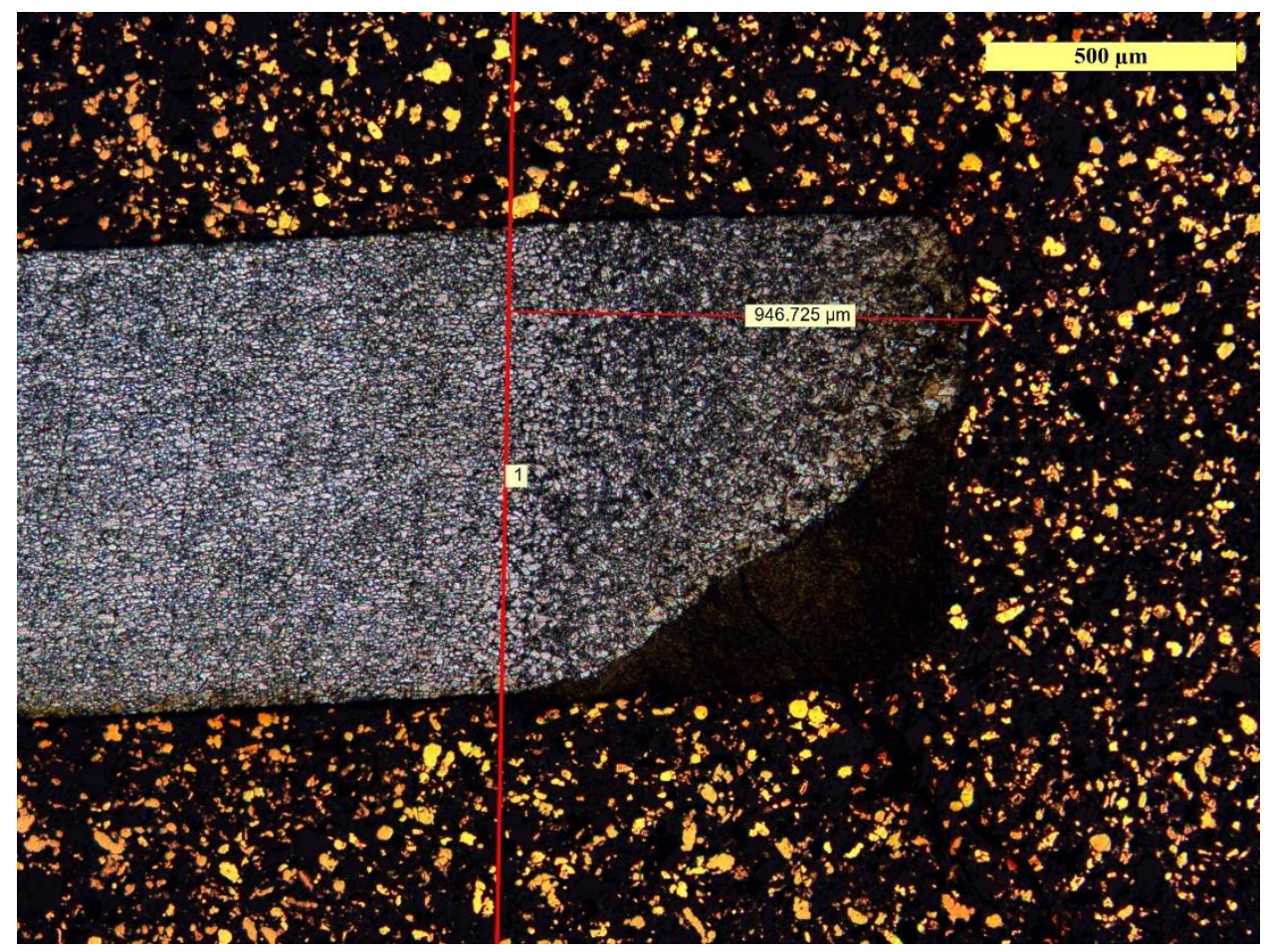

Figure $6 \mathrm{HAZ}$ measured for Trial four top sample

The HAZ analysis results ( table 6 ) showed a high heat impact on the bottom sheets compared to the top side. The model with a smaller gap possessed a lower value in comparison with $15 \mathrm{~mm}$ gap model or $20 \mathrm{~mm}$. The minimum value measured among the top sheets was $0.632 \mathrm{~mm}$ using parameters of the trial 7 whereas the maximum size was $1.441 \mathrm{~mm}$ with trial 6. The bottom samples exhibited a minimum size of $1.245 \mathrm{~mm}$ with trial 9 and a maximum of $3.446 \mathrm{~mm}$ trial 5 .

\subsection{Hardness}

Serie of micro hardening tests were performed to find out the maximum hardness change in the material for each trial. The punching started at $0.1 \mathrm{~mm}$ from the edge of the cut up to $5 \mathrm{~mm}$ using $0.3 \mathrm{~mm}$ steps, this should cover all the altered area[42]. Struers Durascan 70 model machine Vickers Microhardness HV was used for the tests with $1 \mathrm{~kg}$ force load applied for 12 second. The hardness of the unaffected metal base was measured priory to the test and obtained an average value of HV 123. The maximum hardness values measured, and the hardness proportion increase are shown int the table 8 below.

Table 8 Hardness test values and percentage of change

\begin{tabular}{lccccc}
\hline Samples & & \multicolumn{4}{c}{ Hardness (HV) } \\
\cline { 2 - 6 } & & \multicolumn{3}{c}{ Top Sample } & \multicolumn{2}{c}{ Bottom Sample } \\
\cline { 2 - 6 } & & HV Max & Hardness Change & HV Max & Hardness Change \\
\hline First Jig Model & Trial 1 & 205 & $66.7 \%$ & 199 & $61.79 \%$ \\
\cline { 2 - 6 } 20mm Air Gap & Trial 2 & 177 & $43.9 \%$ & $/$ & $/$ \\
\cline { 2 - 6 } & Trial 3 & 147 & $19.5 \%$ & 157 & $27.6 \%$ \\
\hline Second Jig Model & Trial 4 & 172 & $39.8 \%$ & 174 & $41.6 \%$ \\
\cline { 2 - 6 } 15mm air Gap & Trial 5 & 153 & $24.4 \%$ & 150 & $21.9 \%$ \\
\cline { 2 - 6 } & Trial 6 & 200 & $62.6 \%$ & 200 & $62.6 \%$ \\
\hline Third Jig Model & Trial 7 & 139 & $13 \%$ & 151 & $22.7 \%$ \\
\cline { 2 - 6 } 10mm air Gap & Trial 8 & 132 & $7.3 \%$ & 183 & $48.7 \%$ \\
\cline { 2 - 6 } & Trial 9 & 157 & $27.6 \%$ & 146 & $18.7 \%$ \\
\hline
\end{tabular}

The table above showed that the material hardness was increased in all specimens and was maximal at the edge of the cut varied from $7.3 \%$ to $66.7 \%$ for the top samples whereas the bottom exhibited a change starting from $18.7 \%$ to a 
maximum of $80.5 \%$ increase. The highest hardness value measured was for the models with a larger gaps $20 \mathrm{~mm}$ and $15 \mathrm{~mm}$ trials one and six.

\section{Data Analysis}

This section was carried out to find out the effective parameters which can achieve a simultaneous cut in both sheets and at the same time reduce the material deformation or HAZ size on the top layer to a minimum value possible. Taguchi was employed to optimise the process, Signal to Noise $(\mathrm{S} / \mathrm{N})$ ratio can identify the optimal parameters that minimise the phenomenon, the highest $\mathrm{S} / \mathrm{N}$ Ratio levels can be selected as the optimal settings for the process[43]. Smaller is the better option was chosen for the analysis to reduce the phenomenon in this study. The equation (1) to minimise the defects is given as follows[44]:

$$
S / N=-10 \log \frac{1}{n} \sum_{i=1}^{n} Y^{2}
$$

$\mathrm{Y}$ is the observed value (response) and $\mathrm{n}$ is the number of trials made, the table below summarised data collected from the tests results.

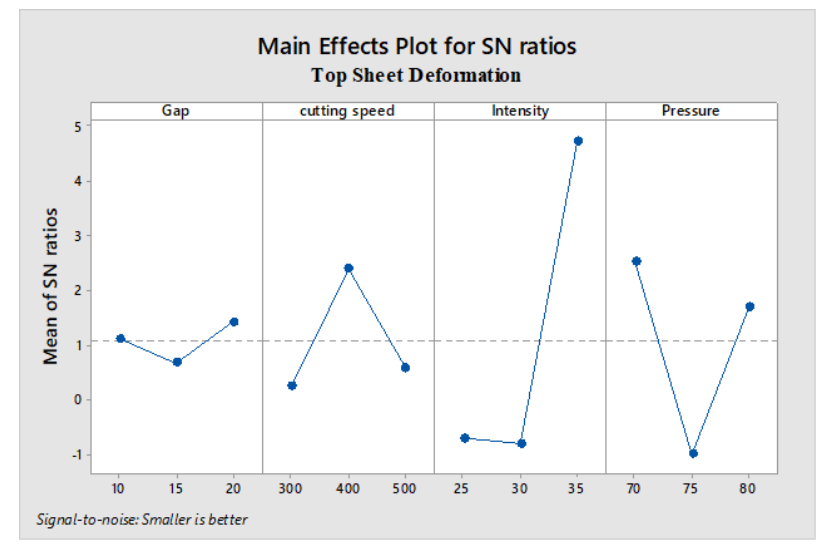

(a)

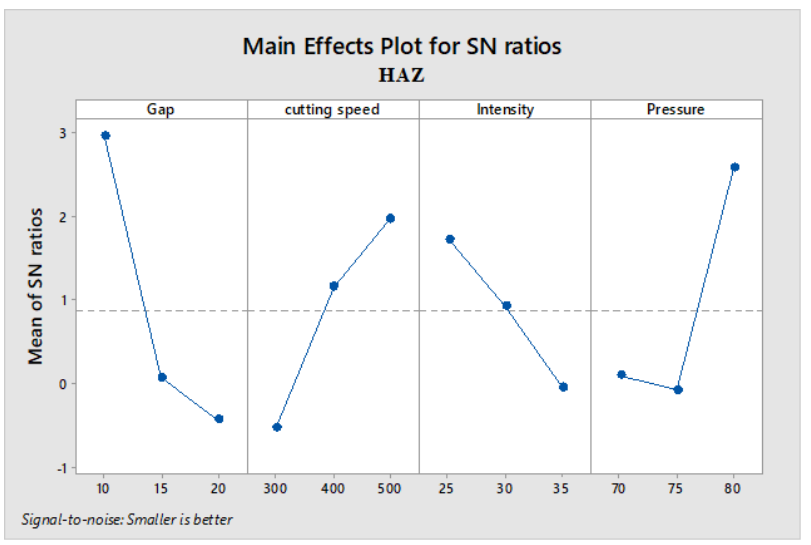

(b)

Figure 7 Main Effect Plot S/N Ratio, (a) top sheets deformation, (b) top sheets heat affected zones

The $\mathrm{S} / \mathrm{N}$ Ratio graphs above indicates the optimal parameters required to cut a three-dimensional part. To achieve less deformation possible on the top sheet then it is recommended to operate the plasma machine at cutting speed level two $400 \mathrm{~mm} / \mathrm{min}$, Pressure at level one $70 \mathrm{Psi}$, Intensity at level three $35 \mathrm{~A}$ using a larger gap at level three $20 \mathrm{~mm}$. To minimise the Heat Affected Zones on the top sheet it is necessary to use Cutting speed at level three $500 \mathrm{~mm} / \mathrm{min}$, pressure at level three 80 Psi, Intensity at level one 25 A using a smaller gap level one $10 \mathrm{~mm}$.

\subsection{Analysis of Variance}

ANOVA is a reliable statistical tool widely used to analyse data and the effect of the parameters[45]. An approximative percentage of the controlled variables effect that have the highest influence on the response can be estimated, the analysis was performed at $95 \%$ level significance. The results are shown in the table 10 below.

Table 9 Effects Contribution

\begin{tabular}{lcc}
\hline Source & \multicolumn{2}{c}{ Contribution } \\
\cline { 2 - 3 } & Top Sheet Deformation & HAZ \\
Intensity & $63.93 \%$ & $8.75 \%$ \\
Pressure & $26.36 \%$ & $28.61 \%$ \\
Gap & $2.24 \%$ & $37.31 \%$ \\
Cutting Speed & $7.47 \%$ & $25.33 \%$ \\
\hline
\end{tabular}

The table above showed that the top sheet deformation is mostly affected by the intensity gas pressure at respectively $63.93 \%$ and $36.36 \%$, the remaining factors did not show a considerable influence. However, gap, pressure and cutting 
speed were the most influential factors affecting the HAZ on the top sheet at $37.31 \%, 28.61 \%$ and $25.33 \%$ respectively, the impact of the intensity was small. The results obtained showed that there was a statistical evidence that the intensity had significant effect on the top sheet deformation with a P-Value of 0.034. However, there was no statistical evidence of the effect significance for any independent parameters on the HAZ as P-values obtained were greater than 0.05, the analysis was done at $95 \%$ level of confidence.

\subsection{Interactions with the Gap Distance}

Interaction plot graph in picture 9 below illustrate the effect of the gap distance on the response depending on the level of the second parameter. The deformation on the top sheet can be reduced when cutting two separate layers simultaneously if the largest gap $20 \mathrm{~mm}$ is processed using either parameter at settings level three. The $10 \mathrm{~mm}$ gap distance associated with pressure 70 Psi also showed a little deformation. However, $15 \mathrm{~mm}$ gap did not show a big difference between pressure's settings, but a slight improvement can be seen using 75 Psi. Cutting speed at level two $400 \mathrm{~mm} / \mathrm{min}$ can result to a small deformation if associated with a small gap $10 \mathrm{~mm}$ but when $15 \mathrm{~mm}$ gap model is used then the speed settings have only a small effect with a slight improvement seen using $300 \mathrm{~mm} / \mathrm{min}$. The intensity at level three 35A would show less deformation cutting any gap.

The HAZ showed a better result and size reduction when $20 \mathrm{~mm}$ gap is used with either parameter at setting level three. The gap distance $15 \mathrm{~mm}$ would require using pressure setting 80 Psi to obtain less HAZ whereas 10mm gap a slight improvement can be seen if 75 Psi pressure is used. The cutting speed at level two $400 \mathrm{~mm} / \mathrm{min}$ is suitable for $15 \mathrm{~mm}$ gap but for $10 \mathrm{~mm}$ gap it is adequate to use level three $500 \mathrm{~mm} / \mathrm{min}$ even though it showed only a small difference. Intensity is more effective if lower setting at level one $25 \mathrm{~A}$ is used to perform a cut on either 15 or $10 \mathrm{~mm}$ gaps. Even though the graphs showed an interaction effect. However, there is no statistical evidence that these interactions are significant as the P-Values were above $5 \%$.

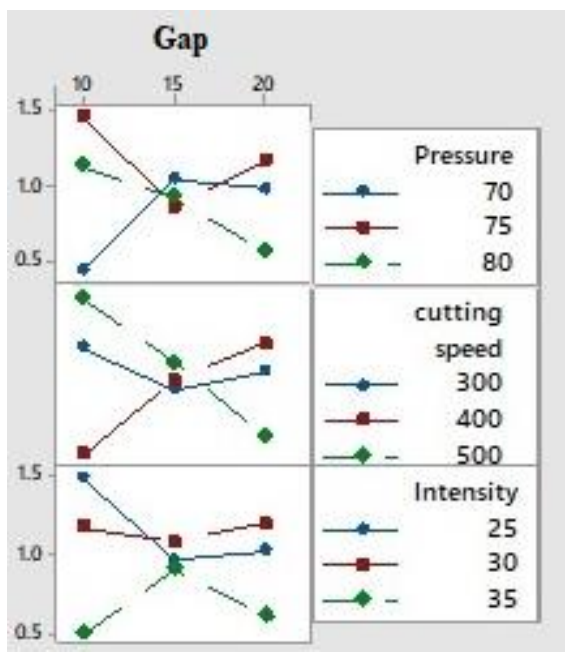

(a)

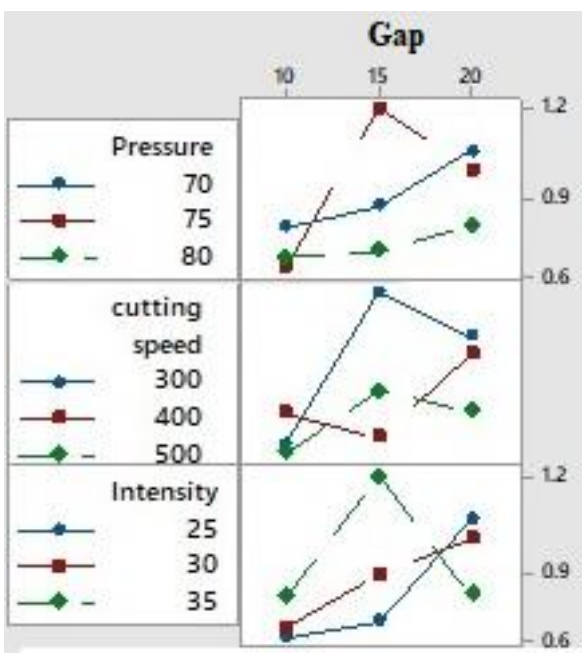

(b)

Figure 8: Gap Interaction, (a) top sheet deformation and (b) heat affected zones on the top sheet.

\subsection{Surface Plot}

The surface plot in picture 10 below shows the response reaction with the two most influencial plasma parameters for both phenomenon material deformation and heat affected zones in the top sheet. When cutting two layers simultaneously, the minimum deformation can be obtained when the machine is operating at power level three (Intensity $35 \mathrm{~A}$ ) using the pressure at level one, the highest value of the deformation can be obtained if the power is used at level one associated with pressure gas at level two. The HAZ showed that a lower value can be obtained when using a small gaps (level one primarely) especially when associated with average pressure gaz (level two), increasing the gap would result to an increase of the phenomenon especially when low pressures are used. 


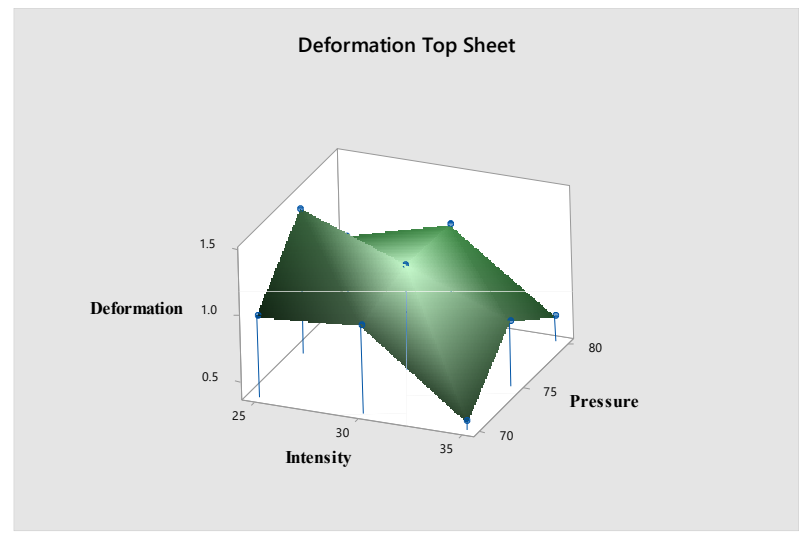

(a)

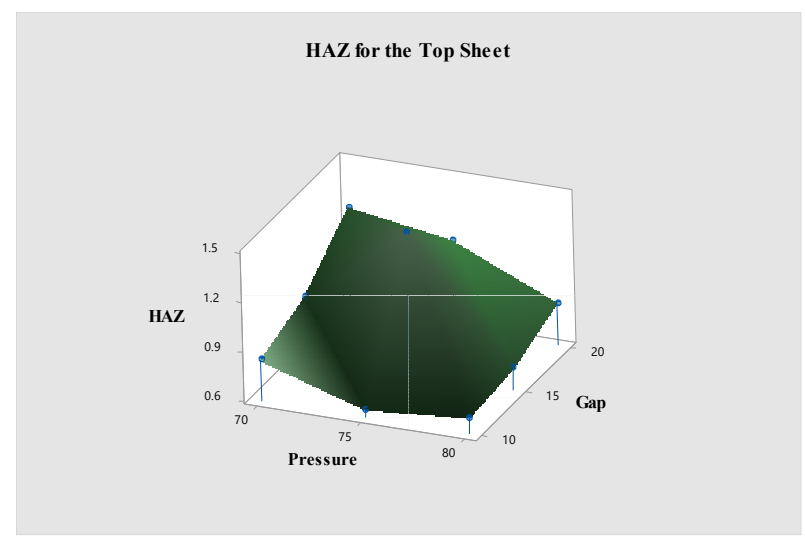

(b)

Figure 9: Surface Plot for top sheets, (a) deformation, (b) HAZ

\subsection{Regression Model}

Regression models were constructed to assess the strength of the relationship between the input parameters and the output variables. The objective of this section was to estimate the response based on what learnt and observed from the experiments performed before. ANOVA has shown in the fits graphs picture 11 below that for both responses, residuals were spaced and falling randomly around the horizontal zero axis and were not following any pattern which meant that errors were unpredictable[46]. The graphs for normal plot in picture 12 showed that the variation and the distribution of the residuals was similar for each level with no outliers observed. The two assumptions were necessary to conclude that there was a linear relationship between the factors and the response. Therefore, it was possible to build a model for regression and the coefficients can be trusted[47].

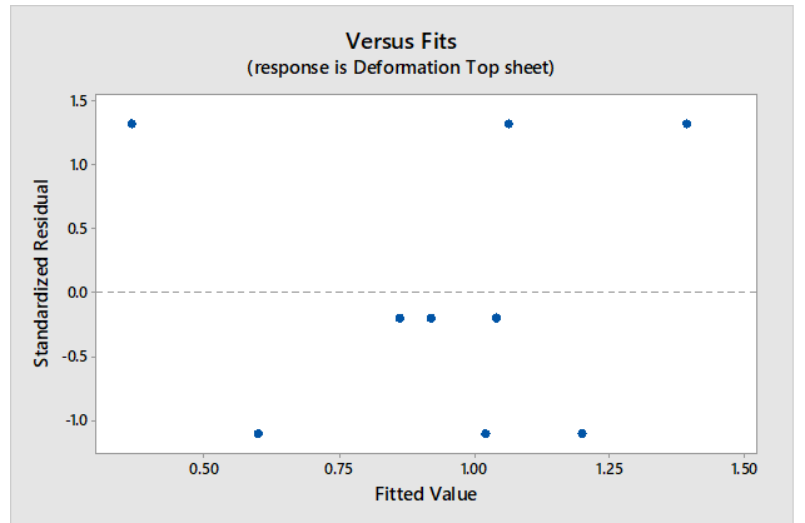

(a)

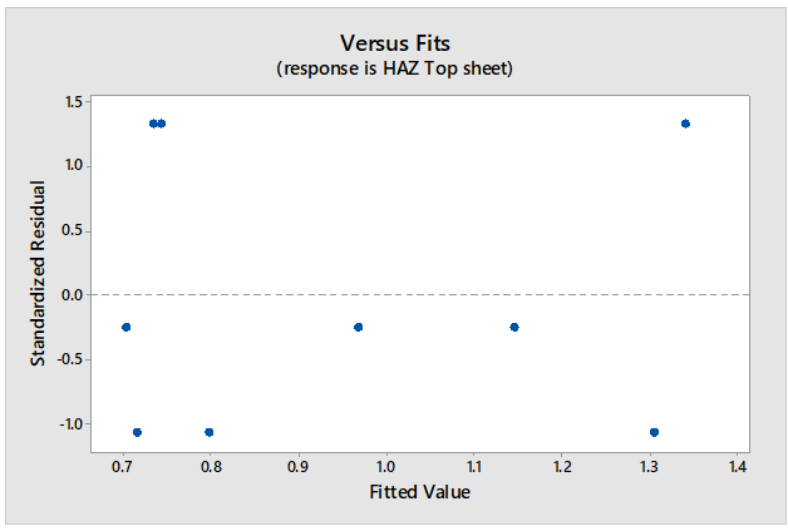

(b)

Figure 10: Fits graph (ANOVA) top sheets, (a) deformation, (b) HAZ 


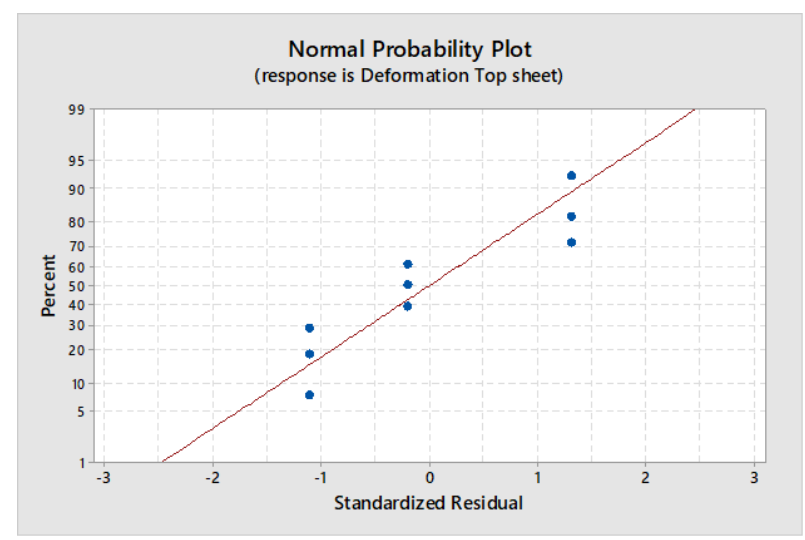

(a)

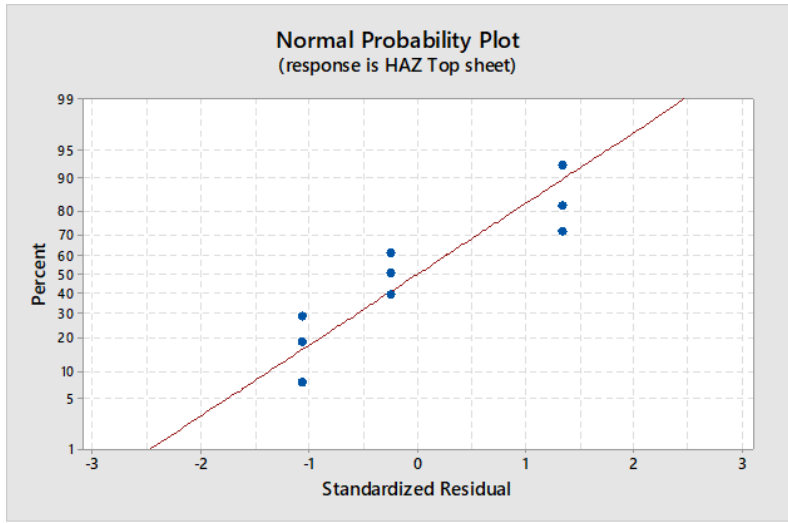

(b)

Figure 11: Residuals graph for top sheet, (a) deformation, (b) HAZ

Person's correlation analysis showed that there was no multicolliniality between the independent variables for both phenomenon. Furthermore, a good regression model required the residuals to be scattered along the diagonal and close to the theoritical line with small errors. Based on the picture 13 below, it is clear that residuals were normally distributed and close to the line. Hence, a trusted prediction models can be constructed.[48]

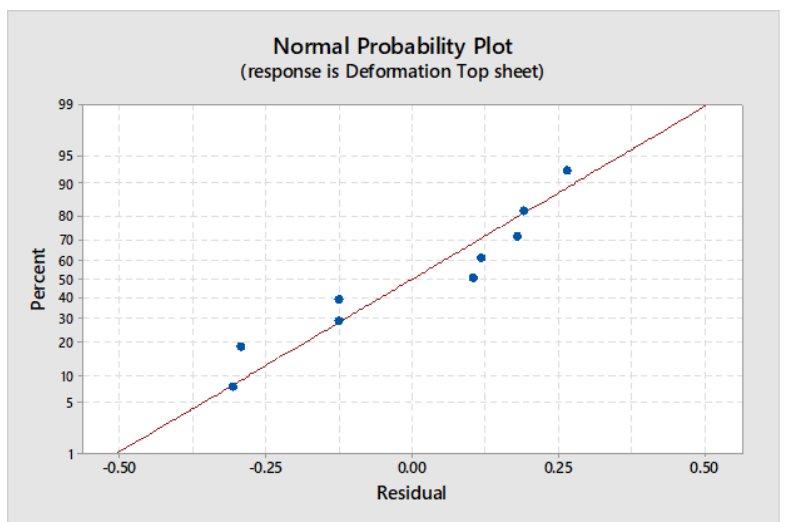

(a)

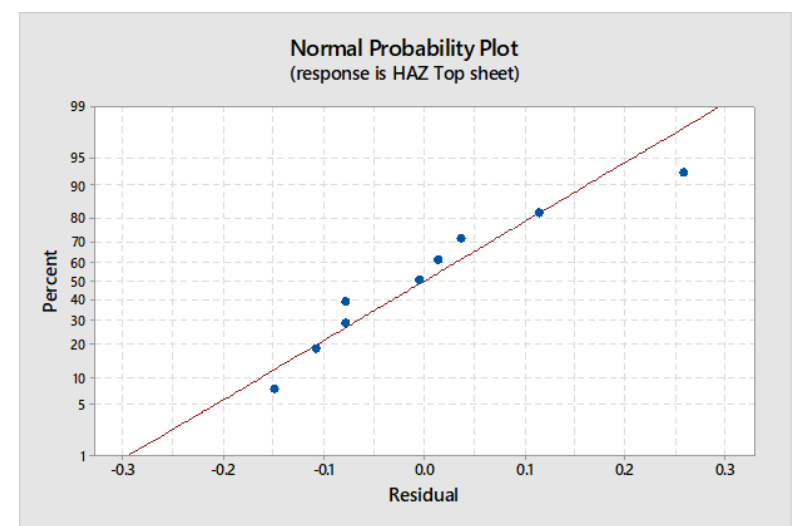

(b)

Fig 12 Probability Plot top sheets, (a) Deformation and (b) HAZ

In this study, more than one variable were analyased. Therefore, the general multi-variable linear regression model (2) is given as follows[49]:

$$
y=b_{o}+b_{1} x_{1}+b_{2} x_{2}+\ldots+b_{i} x_{i}+\ldots+b_{k} x_{k}+\varepsilon
$$

y Observed value (response)

$\mathrm{x}_{1}$ to $\mathrm{x}_{\mathrm{k}}$ are the independent parameters

$\mathrm{b}_{\mathrm{o}}$ is the $\mathrm{Y}$ intercept (prediction of the response when parameters suposed equal to zero)

$b_{1} \rightarrow b_{k}:$ are the coeffients of the regression or Slops ( $y$ change with $b$ value for each one unit change of $x$ while the remaining parameters stay constant)

$\varepsilon$ is the error term

$\mathrm{k}$ is the number of parameters

The number of parameters involved in this regression were four parameters Itensity, pressure, gap, cutting speed for one response then we obtain the following equation (3):

$$
y=b_{\circ}+b_{1} x_{1}+b_{2} x_{2}+b_{3} x_{3}+b_{4} x_{4}+\varepsilon
$$

Where respectively $\mathrm{X}_{1}, \mathrm{X}_{2}$ and $\mathrm{X}_{3}$ and $\mathrm{X} 4$ are intensity, pressure, gap and cutting speed. The multi-variables regression equations obtained from Minitab (4) and (5) are given as follows: 


\title{
Deformation Top Sheet $(\mathrm{mm})=2.15-0.0503 \times$ Intensity $(\mathrm{A})+0.0053 \times$ Pressure $($ Psi) $-0.0107 \times$ Gap $(\mathrm{mm})$ \\ $+0.00015 \times$ Cutting Speed $(\mathrm{mm} / \mathrm{min})$

\begin{abstract}
HAZ Top Sheet $(\mathrm{mm})=2.39+0.0184^{\times}$Intensity $(A)-0.0254 \times$ Pressure $($ Psi $)+0.0348 \times$ Gap $(\mathrm{mm})$ - $0.001537 \times$ Cutting Speed $(\mathrm{mm} / \mathrm{min})$

(5)
\end{abstract}

The results obtained from the regression analysis in Minitab showed that R-squared for the heat affected zones on the top sheet was $78 \%$ whereas the for the deformation was $53 \%$ at $95 \%$ confidence. R Squared was known as the coefficient of determination that can indicate the strength of the relation between the factors and the response[50]. $\mathrm{R}^{2}$ is ranging between $0 \leq \mathrm{R}^{2} \leq 1$ (or $100 \%$ ). $\mathrm{R}^{2}$ close or equal to zero means that the model is poorly fit whereas $\mathrm{R}^{2}$ close or equal to 1 represents the ideal model fit or that residuals are scattered along the regression line without errors[51]. $\mathrm{R}^{2}$ can give an indication of the percentage of variability in response $\mathrm{Y}$ that can be explained by the variability of the parameters used, the rest of the proportion $\left(1-\mathrm{R}^{2}\right)$ remain unknown due to the errors, this means that proportion $\left(1-\mathrm{R}^{2}\right)$ does not represent the inadequacy of the model. A high or low value of $\mathrm{R}^{2}$ generally can give an indication of the model strength but it has been proven that $\mathrm{R}^{2}$ can be misleading in some cases, meaning that we could get a poor $\mathrm{R}^{2}$ for a good model and vice versa[52]. J. Frost emphasised that asking the question of how high $\mathrm{R}^{2}$ should be for a good regression model is not appropriate. Therefore, it is recommended to test the model and use the interval of prediction to satisfy the prediction requirements[53].

\subsection{Confirmation tests}

Additional tests were performed to validate the results obtained and assess the strength of the relationship between the variables. Initially two trials were carried out to verify the optimum parameters and their level of improvement. Second trials were made to demonstrate the validity of the regression model, the parameters of the plasma machining were selected randomly within the population used before, then results were compared against the predicted responses calculated using the mathematical model. Eight tests were made in total including the optimal tests as seen in the tables below 10 and 11. Furthermore, the regression equations were tested also against the response values obtained at the beginning of this work experiments to check if results were falling within the prediction interval. Specimens collected from validation tests were processed and assessed in the same manner than the samples made previously.

\subsubsection{Optimum parameters verification}

Table 10 Optimal parameters tests

\begin{tabular}{cccccc}
\hline & $\begin{array}{c}\text { Gap } \\
(\mathbf{m m})\end{array}$ & $\begin{array}{c}\text { Cutting Speed } \\
(\mathbf{m m} / \mathbf{m i n})\end{array}$ & $\begin{array}{c}\text { Pressure } \\
(\mathbf{P s i})\end{array}$ & $\begin{array}{c}\text { Intensity } \\
(\mathbf{A})\end{array}$ & $\begin{array}{c}\text { Measured } \\
(\mathbf{m m})\end{array}$ \\
\hline Deformation & 20 & 400 & 70 & 35 & 0.41 \\
HAZ & 10 & 500 & 80 & 25 & 0.38 \\
\hline
\end{tabular}

\subsubsection{Regression Equations tests}

Table 11 Regression Tests

\begin{tabular}{|c|c|c|c|c|c|c|c|c|c|c|}
\hline & \multirow{2}{*}{$\begin{array}{c}\text { Gap } \\
(\mathrm{mm})\end{array}$} & \multirow{2}{*}{$\begin{array}{c}\text { Cutting } \\
\text { Speed } \\
(\mathrm{mm} / \mathrm{min})\end{array}$} & \multirow{2}{*}{$\begin{array}{l}\text { Pressure } \\
\text { (Psi) }\end{array}$} & \multirow{2}{*}{$\begin{array}{c}\text { Intensity } \\
\text { (A) }\end{array}$} & \multicolumn{3}{|c|}{ Deformation (mm) } & \multicolumn{3}{|c|}{ HAZ (mm) } \\
\hline & & & & & Measured & Predicted & $\begin{array}{c}\text { Prediction } \\
\text { Interval }\end{array}$ & Measured & Predicted & $\begin{array}{c}\text { Prediction } \\
\text { Interval }\end{array}$ \\
\hline Test 1 & 20 & 500 & 70 & 25 & 0.64 & 1.125 & $\leq 2.258$ & 1.1 & 0.993 & $0.33-1.65$ \\
\hline Test 2 & 20 & 300 & 80 & 35 & 0.68 & 0.645 & $\leq 1.778$ & 1.3 & 1.23 & $0.57-1.89$ \\
\hline Test 3 & 15 & 500 & 70 & 25 & 1.11 & 1.178 & $\leq 2.25$ & 0.85 & 0.819 & $0.19-1.44$ \\
\hline Test4 & 10 & 300 & 80 & 35 & 1.19 & 0.752 & $\leq 1.88$ & 0.9 & 0.882 & $0.22-1.54$ \\
\hline Test 5 & 20 & 400 & 70 & 35 & 0.41 & 0.607 & $\leq 1.68$ & 0.8 & 1.33 & $0.7-1.96$ \\
\hline Test 6 & 10 & 500 & 80 & 25 & 1.06 & 1.28 & $0.15-2.42$ & 0.38 & 0.391 & $\leq 1.05$ \\
\hline
\end{tabular}


The validation tests result showed a better quality using optimal parameters for both responses. Very small reduction obtained for the top sheet deformation compared to the results measured in previous experiments whereas the HAZ result obtained from the validation displayed a lower HAZ width and a decrease in size to just below $50 \%$ using the optimal parameters. The values measured in the validation tests were all close to the ones predicted by the equations and none of them fell outside the predicted interval, this showed that the regression model fit properly and can be trusted.

\section{Discussion and Future Work}

The tests showed that the plasma technique can perform a cut in two separate layers simultaneously. Re-employment of the plasma heat power exiting the first layer was possible. The energy leaving the material during the plasma cutting does not completely dissipate in the atmosphere or absorbed. The assumption made in the literature review that only waterjet among the non-traditional techniques possessed the ability to cut two layers simultaneously[5] was proven to be not accurate. The tests revealed that the capability of processing two layers was subject to the gap distance.

Tests showed that when cutting simultaneously two separated sheets the bottom layers would be affected more than the top sheets, excluding the hardness which did not show a big change between the top and bottom layers, this contradicted what the study assumed at the beginning of the tests as the top sheets were exposed to excess heat. Dross size registered on the top sheet was varied from $1.3 \mathrm{~mm}$ to $2.7 \mathrm{~mm}$ whereas on the bottom sheets it showed a minimum of $1.9 \mathrm{~mm}$, the results indicated that a second processing might be required to clean the edge. The kerf size was almost steady in the top sheets for all trials with less than $2 \mathrm{~mm}$ width measured whereas the bottom sheets kerf showed a higher value to almost $5 \mathrm{~mm}$ width, the maximum size was registered for lowest gap. There was a noticeable reduction in size in the bottom samples compared to the top for all trials, the maximum loss of $10.27 \%$ was registered for the $15 \mathrm{~mm}$ gap, this might be the cause of the plasma flame shape diverged after exiting the first sheet.

The deformation registered for the top sheets was varied from $0.42 \mathrm{~mm}$ to $1.45 \mathrm{~mm}$ whereas the bottom showed a maximum deformation of $3.9 \mathrm{~mm}$. The larger gap showed less sheet deformation value compared to narrower gaps, this might be due to wider space between sheets allowed more room for aeration and heat dissipation in the atmosphere. Analysis of variance showed that the top sheet was mainly affected by the intensity $63.93 \%$ with the evidence that the effect was statistically significant followed by the pressure at $26.36 \%$ with no evidence of statistical significance. 3D surface plot showed that cutting double layered parts using a low power and low pressure would result to a high deformation, therefore it was recommended to employ a high-power intensity with a lowest gas pressure. Taguchi suggested that the best parameters to use to lower the top sheet deformation were cutting speed $400 \mathrm{~mm} / \mathrm{min}$, pressure 70 Psi and $35 \mathrm{~A}$ intensity using large gap $20 \mathrm{~mm}$, but this showed a very small improvement in deformation from $0.42 \mathrm{~mm}$ to $0.41 \mathrm{~mm}$ at the validation.

The heat affected zones measured varied from 0.632 to $1.441 \mathrm{~mm}$ on the top sheet, the values measured were higher in the wider gap test model. The lower samples were varied from 1.245 to $3.446 \mathrm{~mm}$. The parameters that showed an effect on the response were the gap at $37.31 \%$, pressure $28.61 \%$ and cutting speed $25.33 \%$. However, there was no evidence statistically that these effects were significant, this might be the cause of ANOVA failed to detect the significance due to small size of samples. The surface plot showed that large gap distance between sheets would result in general to a high defect when a low pressure is used. Therefore, it is recommended in this case to attribute a high pressure for a better result. To achieve lowest heat affected zones width then the suggestion was to cut smaller gaps associated with the right pressure which is not high nor low. Taguchi showed that cutting speed $500 \mathrm{~mm} / \mathrm{min}$, pressure 80 Psi, intensity 25 A and $10 \mathrm{~mm}$ gap were the best option to minimise heat affected zones, the validation tests showed a reduction in size by almost half in from 0.632 to $0.38 \mathrm{~mm}$.

Multi-linear regression equations for deformation and HAZ on the top sheet were tested, the results showed a close values between the estimated and the measured ones and none of the measured values were outside the interval of prediction. The results showed that the two models were fitting adequately and there was a substantial relationship between the input and output variables.

\subsection{Future work}

There are some points worth investigating which could be beneficial and broaden the range of this work. The actual study was carried out considering the budget of the initial investment, this would explain the use of an adequate basic plasma model for the experiments. Cutting edge plasma technology used nowadays is the high density plasma (HD) known for their capability to achieve a high quality cut similar to laser technique[27]. Therefore, this would be interesting repeating the same experiments using this model of Plasma and assess the quality achieved then compare the results to the ones obtained in this paper (including costing). Thickness of the sheets can be added as one of the input variables, this would require a very large size of trials to assess the quality. Due to the task complexity and the number of samples 
to assess, same population for the input variables were used from the beginning to the end. Therefore, taking a step further and build equations for prediction that can estimate the response for any given parameter would be valuable especially if the equations are translated into an algorithm which can be incorporated in a mechanised plasma cutter software.

\section{Abbreviation}

HAZ: Heat Affected Zones

ANOVA: Analysis OF Variance

HD: High Density

3D: Three-Dimensional

2D: Two-dimensional

CNC: Computer Numerical Control

\section{Funding}

This research did not receive any specific grant from funding agencies in the public, commercial, or not-for-profit sectors

III. Conflicts of interest/Competing interests (This work was done with no conflicts of interests or competing)

\section{Acknowledgement}

I express my gratitude to the advanced research forming centre, Strathclyde university, Kelvin College and Clyde College in Glasgow, Allied vehicles and all who supported this work.

\section{Vitae}

I am a student researcher at my last year of Doctorate program in advanced Manufacturing. I am doing my project in the automotive manufacturing (vehicles conversion) as part of the research and development team for three years, my research was focused on the possibility of automation within a medium or small factories, my project was to design an automated cutting tool that can overcome the issues encountered during the cutting stage and also improve the efficiency of work. In addition, experiments were required to answer the research questions. Experiments were carried out in Glasgow between the advanced forming research centre and Strathclyde university. I also possess a degree of master's science in advanced manufacturing and mechanical engineering.

\section{REFERENCES}

[1] Andrés, D., García, T., Cicero, S., Lacalle, R., Álvarez, J. A., Martín-Meizoso, A., Aldazabal, J., Bannister, A., and Klimpel, A., 2016, 'Characterization of Heat Affected Zones Produced by Thermal Cutting Processes by Means of Small Punch Tests', Mater. Charact., 119, p. 55 .

[2] Nemchinsky, V., 2017, 'Heat Transfer in Plasma Arc Cutting', Handbook of Thermal Science and Engineering, Springer, p. 3.

[3] Kechagias, J., Petousis, M., Vidakis, N., and Mastorakis, N., 2017, 'Plasma Arc Cutting Dimensional Accuracy Optimization Employing the Parameter Design Approach', ITM Web Conf., 9(03004), p. 1.

[4] Nemchinsky, V. A., and Severance, W. S., 2006, 'What We Know and What We Do Not Know about Plasma Arc Cutting', J. Phys. D. Appl. Phys., 39(22), p. R424.

[5] Krajcarz, D., 2014, 'Comparison Metal Water Jet Cutting with Laser and Plasma Cutting', Procedia Engineering, 24th DAAAM International Symposium on Intelligent Manufacturing and Automation, Elsevier, Science Direct, Kielce, Poland, p. 840.

[6] Nedic, B., Janković, M., Radovanović, M., Lakic, G. G., Nedić, B., and Lakić, G. G., 2013, 'Quality of Plasma Cutting', 13th International Conference on Tribology - Serbiatrib'13, Serbian Tribology Society, Kragujevac, Serbia, p. 314

[7] Chamarthi, S., Reddy, N. S., Elipey, M. K., and Reddy, D. V. R., 2013, 'Investigation Analysis of Plasma Arc Cutting Parameters on the Unevenness Surface of Hardox-400 Material', Procedia Eng., 64, p. 855.

[8] Balasundaram, H. R. R., and Karthikeyan, N. G. N., 2018, 'Experimental Investigation of Cut Quality Characteristics on SS321 Using Plasma Arc Cutting', J. Brazilian Soc. Mech. Sci. Eng., 40(2), pp. 3-11/60.

[9] Krajcarz, D., 2014, 'Comparison Metal Water Jet Cutting with Laser and Plasma Cutting', Procedia Engineering, p. 840.

[10] Iosub, A., Nagit, G., and Negoescu, F., 2008, 'Plasma Cutting of Composite Materials', Int. J. Mater. Form., 1(SUPPL. 1), pp. 1347-1350.

[11] Morphy, G., 2000, Hydroformed Automotive Components: Manufacturing Cost Considerations.

[12] Kechagias, J. D., Aslani, K. E., Fountas, N. A., Vaxevanidis, N. M., and Manolakos, D. E., 2020, 'A Comparative Investigation of Taguchi and Full Factorial Design for Machinability Prediction in Turning of a Titanium Alloy', Meas. J. Int. Meas. Confed., 151, p. 107213.

[13] Şen, N., and Baykal, Y., 2019, 'Development of Car Wishbone Using Sheet Metal Tearing Process via the Theory of Inventive ProblemSolving (TRIZ) Method', J. Brazilian Soc. Mech. Sci. Eng., 41(3), p. 390.

[14] Escamilla-Salazar, I. G., Torres-Trevi no, L., and Gonzalez-Ortiz, B., 2016, 'Intelligent Parameter Identification of Machining Ti64 Alloy', Int. J. Adv. Manuf. Technol., 86(5-8), p. 1998. 
Mohd Sazali Md Said, Jaharah A. Ghani, Mohd Shahir Kassim, Siti Haryani Tomadi, C. H., 2013, 'Comparison between Taguchi Method and Response Surface Methodology (RSM) In Optimizing Machining Condition', 1st International Conference on Robust Quality Engineering (ICRQE 2013), P.D.Z.M. Prof. Dr. Bo Bergman, Prof. Dr. Masayoshi Koike, ed., International Conference on Robust Quality Engineering Editorial, Kuala Lumpur, Malaysia, pp. 60-64.

[16] Rana, K., Kaushik, P., and Chaudhary, S., 2013, 'Optimization of Plasma Arc Cutting by Applying Taguchi Method', Int. J. Enhanc. Res. Sci. Technol. Eng., 2(7), pp. 106-110.

[17] Abe, J. O., Popoola, O. M., Popoola, A. P. I., Ajenifuja, E., and Adebiyi, D. I., 2019, ‘Application of Taguchi Design Method for Optimization of Spark Plasma Sintering Process Parameters for Ti-6Al-4V/ h -BN Binary Composite', Eng. Res. Express, 1(2), p. 12.

[18] Adalarasan, R., Santhanakumar, M., and Rajmohan, M., 2015, 'Application of Grey Taguchi-Based Response Surface Methodology (GTRSM) for Optimizing the Plasma Arc Cutting Parameters of 304L Stainless Steel', Int. J. Adv. Manuf. Technol., 78(5-8), pp. 1161-1170.

[19] Freton, P., Gonzalez, J. J., Gleizes, A., Peyret, F. C., Caillibotte, G., and Delzenne, M., 2002, 'Numerical and Experimental Study of a Plasma Cutting Torch', J. Phys. D. Appl. Phys., 35, p. 115.

[20] GHANE, D. B., ABHANG, L. B., MAKASARE, P. A., and KHARAD, B. N., 2019, 'OPTIMIZATION ON OPERATING PARAMETERS OF CNC PLASMA MACHINE BY EXPERIMENTATION’, J. Instrum. Control Eng., 7(1), pp. $26-33$.

[21] Çelik, Y. H., 2013, 'Investigating the Effects of Cutting Parameters on Materials Cut in CNC Plasma', Mater. Manuf. Process., 28(10), pp. $1053-1060$

[22] Lazarevic, D. A., 2014, 'Experimental Research of the Plasma Arc Cutting Process’, Orig. Sci. Pap. iipp, 124(304), p. 291.

[23] Gariboldi, E., and Previtali, B., 2005, ‘High Tolerance Plasma Arc Cutting of Commercially Pure Titanium’, J. Mater. Process. Technol., 160(1), pp. 77-89.

[24] Ilii, S. M., and Coteaţă, M., 2009, 'Plasma Arc Cutting Cost', Int. J. Mater. Form., 2(SUPPL. 1), pp. 689-692.

[25] Wang, J., Hoang, T., Floyd, E. L., and Regens, J. L., 2017, 'Characterization of Particulate Fume and Oxides Emission from Stainless Steel Plasma Cutting’, Ann. Work Expo. Heal., 61(3), pp. 311-320.

[26] Kavka, T., Mašláni, A., Hrabovský, M., Křenek, P., Stehrer, T., and Pauser, H., 2013, 'Experimental Study of the Effect of Gas Nature on Plasma Arc Cutting of Mild Steel', J. Phys. D. Appl. Phys., 46(22), pp. 1-13.

[27] Rakhimyanov, K., Rakhimyanov, A., and Heifetz, M., 2015, 'High-Precision Plasma Cutting of the Steel - Aluminum 'Bimetallic Composition“", Appl. Mech. Mater., 788, p. 41.

[28] Leander Schleuss, Thomas Richter, Ralf Ossenbrink, and Vesselin Michailov, 2015, 'Plasma Cutting of Structured Sheet Metals in Comparison with Laser Beam Cutting', J. Mater. Sci. Eng. B, 5(4), p. 143.

[29] Kavka, T., Tossen, S., Maslani, A., Konrad, M., Pauser, H., and Stehrer, T., 2014, 'Experimental Investigation of Energy Balance in Plasma Arc Cutting Process', J. Phys. Conf. Ser., 511(1), p. 6.

[30] ArcelorMittal, 2018, 'Extract from the Automotive Product Catalogue - High Formability Steels for Drawing Drawing Steels Application', Automot. Worldw., p. 105.

[31] Vasile, R., Racz, S. G., and Bologa, O., 2017, 'Experimental and Numerical Investigations of the Steel Sheets Formability with Hydroforming', MATEC Web Conf., 94, p. 2.

[32] Hypertherm, 2013, Hypertherm, Powermax 1250, Plasma Arc Cutting System, Operator Manual.

[33] GOM., 2018, 'Atos 3D Scanner, Capture 3D, Gom.', GOM [Online]. Available: https://www.capture3d.com/3d-metrology-solutions/3dscanners/atos-compact-scan. [Accessed: 23-Aug-2019].

[34] Capture 3D, 2020, 'GOM ATOS Triple Scan | Capture 3D', Gom [Online]. Available: https://www.capture3d.com/3d-metrologysolutions/3d-scanners/atos-triple-scan. [Accessed: 04-Jun-2020].

[35] Kim, C., Lee, T. I., Kim, M. S., and Kim, T. S., 2015, 'Warpage Analysis of Electroplated Cu Films on Fiber-Reinforced Polymer Packaging Substrates', Polymers (Basel)., 7(6), p. 989.

[36] Jim Colt, 2015, 'The Welder, Cutting and Weld Prep, Troubleshooting CNC Plasma Cutting, Part II', Fabr. [Online]. Available: https://www.thefabricator.com/thewelder/article/cuttingweldprep/troubleshooting-cnc-plasma-cutting-part-ii. [Accessed: 14-Oct-2019]. American Torch Tip, 2017, 'How To Reduce Dross and Slag During Plasma Cutting', ATTC [Online]. Available: https://www.americantorchtip.com/blog/reduce-dross-and-slag-buildup. [Accessed: 14-Oct-2019].

[38] Hypertherm, 2019, 'Troubleshooting Plasma Cutting System Cut Quality Problems - Cut Angularity', Hypertherm Shap. Possibility [Online]. Available: https://www.hypertherm.com/customer-support/getting-the-most-from-your-products/cut-quality/cutangularity/?region=EMEA. [Accessed: 15-Oct-2019].

[39] Sloderbach, Z., and Pajak, J., 2015, 'Determination of Ranges of Components of Heat Affected Zone Including Changes of Structure', Arch. Metall. Mater., 60(4), p. 2608.

[40] The Welding Institute, 'What Is the Heat Affected Zone (HAZ)? - TWI', TWI [Online]. Available: https://www.twi-global.com/technicalknowledge/faqs/what-is-the-heat-affected-zone. [Accessed: 23-Aug-2019].

[41] Thyssenkrupp, 2018, Deep-Drawing Steels DD, DC Und DX: Product Information.

[42] Open University, 2018, 'Plasma Arc Cutting', OpenLearn [Online]. Available: https://www.open.edu/openlearn/science-mathstechnology/engineering-technology/manupedia/plasma-arc-cutting. [Accessed: 11-Nov-2019].

[43] V.N. Gaitonde, S.R. Karnik, J. P. D., 2015, 'Multiple Performance Optimization in Drilling Using Taguchi Method with Utility and Modified Utility Concepts', Sci. Direct, Mater. Form. Mach., p. 104.

[44] Pawar, S. S., and Inamdar, K. H., 2017, 'Analysis of Heat Affected Zone in Plasma Arc Cutting of SS 3161 Plates', ijirset, 6(5), p. 8165.

[45] Sinharay, S., 2010, 'An Overview of Statistics in Education', International Encyclopedia of Education, Elsevier, New Jerzy USA, p. 6.

[46] Jim Frost, 'Check Your Residual Plots to Ensure Trustworthy Regression Results! - Statistics By Jim', Stat. By Jim Mak. Stat. intuitive [Online]. Available: https://statisticsbyjim.com/regression/check-residual-plots-regression-analysis/. [Accessed: 02-Sep-2019].

[47] Minitab, 2019, 'Residual Plots for Fit Regression Model', Minitab [Online]. Available: https://support.minitab.com/en-us/minitab/18/helpand-how-to/modeling-statistics/regression/how-to/fit-regression-model/interpret-the-results/all-statistics-and-graphs/residual-plots/. [Accessed: 05-Nov-2019].

[48] MINITAB BLOG EDITOR, 2013, 'Regression Analysis: How Do I Interpret R-Squared and Assess the Goodness-of-Fit?', MINITAB BLOG [Online]. Available: https://blog.minitab.com/blog/adventures-in-statistics-2/regression-analysis-how-do-i-interpret-r-squared-andassess-the-goodness-of-fit. [Accessed: 31-Aug-2019].

[49] Bremer, M., 2012, 'Multiple Linear Regression', mezeylab, lab members, Math 261 A, (1), p. 18,21,22,23 [Online]. Available: http://mezeylab.cb.bscb.cornell.edu/labmembers/documents/supplement 5 - multiple regression.pdf.

[50] Adam Hayes, 2019, 'R-Squared Definition', Investopedia [Online]. Available: https://www.investopedia.com/terms/r/r-squared.asp. [Accessed: 02-Dec-2019].

[51] Ellis, Agnes Ogee and MarkScibilia, B., Ellis, B. S. and M., Pammer, C., and Steele, C., 2014, 'How High Should R-Squared Be in Regression Analysis?', MINITAB BLOG [Online]. Available: https://blog.minitab.com/blog/adventures-in-statistics-2/how-high-should-rsquared-be-in-regression-analysis. [Accessed: 05-Jan-2020].

[52] Lewis-Beck, M., Bryman, A., and Futing Liao, T., 2012, 'R-Squared', SAGE Encycl. Soc. Sci. Res. Methods, p. 1189.

[53] Frost, J., 2014, 'How High Does R-Squared Need to Be? - Statistics By Jim', Mak. statictics intuitive [Online]. Available: https://statisticsbyjim.com/regression/how-high-r-squared/. [Accessed: 07-Jan-2020]. 